\title{
Evaluation of Mental Index, Mandibular Cortical Index and Panoramic Mandibular Index on Dental Panoramic Radiographs in the Elderly
}

\author{
Esin Hastara \\ H. Huseyin Yilmaz \\ Hikmet Orhanc
}

\begin{abstract}
Objectives: The aims of this study were to evaluate the influence of gender and dental status on the mental index, mandibular cortical index and panoramic mandibular index from dental panoramic radiographs in elderly who had osteoporosis or did not have osteoporosis.

Methods: Panoramic radiographs of 487 elderly dental patients (age range 60-88 years) were evaluated. It were recorded osteoporotic status according to the patients' medical anamnesis and values of the mandibular cortical index (MCI), panoramic mandibular index (PMI), mandibular cortical width (MCW)

Results: Dental status was statistically significantly associated with the mandibular cortical width, panoramic mandibular index and the categories of $\mathrm{MCI}(\mathrm{P}<.05)$. There were statistically different mandibular cortical width and panoramic mandibular index values in patients with osteoporosis and without osteoporosis $(\mathrm{P}<.05)$

Conclusions: Our study showed that there were statistically significant differences according to gender, dental status, and values of the $\mathrm{MCW}, \mathrm{MCl}$ and $\mathrm{PMI}$ between patients with and those without osteoporosis. (Eur J Dent 2011;5:60-67)
\end{abstract}

Key words: Panoramic radiography; Mandibular Cortical Index; Osteoporosis; Elderly.

\footnotetext{
a Department of Oral Diagnosis and Radiology, Faculty of Dentistry, Gaziantep University, Gaziantep, Turkey.

b Department of Oral Diagnosis and Radiology, Faculty of Dentistry, Suleyman Demirel University, Isparta, Turkey.

Department of Animal Science, Genetic and Biometry Unit, Faculty of Agriculture, Suleyman Demirel University, Isparta, Turkey.

- Corresponding author: Dr. Esin Hastar Gaziantep University Faculty of Dentistry, Department of Oral Diagnosis and Radiology, Sehitkamil, Gaziantep, Turkey.

Phone: + 903423610610

E-mail: dtesinahotmail.com
}

\section{INTRODUCTION}

Osteoporosis is a disease characterized by low bone mass and micro-architectural deterioration of bone tissue, leading to bone fragility and enhanced susceptibility to fractures. Osteoporosis is predominantly a condition of the elderly. ${ }^{1,2}$ It affects mostly women, especially after menopause as a result of estrogen withdrawal ("menopausal" osteoporosis). ${ }^{2}$ A major obstacle to combating osteoporosis is the failure to identify individuals who have osteoporosis until the clinical consequences of osteoporosis have occurred (i.e., fractures form with little trauma to the bones). Thus, detection 
of osteoporosis, assessment of bone mass, and identification of fracture risk are important goals when evaluating patients for osteoporosis. ${ }^{3,4}$ Subjects with a self-reported history of osteoporotic fractures also tend to have increased resorption and thinning of the mandibular lower cortex. ${ }^{5}$ Several investigators have stated that osteoporosis results in reduced jaw bone mass and altered mandibular structure, especially of the inferior border (mandibular lower cortex). 6,7

Dental radiographs, especially panoramic images, have been used to predict low bone mineral density in patients. A number of mandibular cortical indices, including the mandibular cortical index (MCI), mandibular cortical width (MCW) and panoramic mandibular index (PMI), have been developed to assess and quantify the quality of mandibular bone mass and to observe signs of resorption on panoramic radiographs for identification of osteopenia. The best established of these is the mental index (MI), which is the mean of the widths of the lower border cortex below the two mental foramina. Osteopenia can be identified by the thinning of the cortex at the lower border of the mandible. A thin mandibular cortical width has been shown to be correlated with reduced skeletal bone mineral density. 4,8-10 The mandibular cortical index describes the porosity of the mandible and is related to the mandibular bone mineral density. Many studies have shown that this index is a useful method of osteoporosis screening. 5,11-14 The panoramic mandibular index is the ratio of the thickness of the mandibular cortex to the distance between the mental foremen and the inferior mandibular cortex. ${ }^{15}$

Although many studies $3,9,10,13,14,16-18$ have evaluated mandibular radiomorphometric indices (MI, $\mathrm{MCl}, \mathrm{PMI}$ as indicators of possible osteoporosis in postmenopausal women, few studies ${ }^{4,8,19}$ have evaluated these measurements in older men.

Because most elderly individuals have more opportunities to visit a dental clinic than to visit a medical clinic for diagnosis of osteoporosis, it is important to determine the relationship between panoramic radiomorphometric indices and skeletal bone mineral density. ${ }^{20}$

The aims of this study were to evaluate the influence of gender and dental status on the mental index, mandibular cortical index, and panoramic mandibular index on dental panoramic radio- graphs in the elderly with osteoporosis and without osteoporosis.

\section{MATERIALS AND METHODS}

Study sample

Four hundred eighty-seven elderly dental patients lage-range 60-88 years, mean age 67.9; 239 men, 248 women) were evaluated at the Department of Oral Diagnosis and Radiology (Suleyman Demirel University, Faculty of Dentistry, Isparta), who were receiving either routine or emergency dental care. Menopausal age in women, the type of denture worn, and oral parafunctions (tooth clenching, tooth-grinding) were recorded for each patient, in addition to the gender, dentition status, age, and osteoporotic status according to the patients' medical anamnesis.

All panoramic images were made using panoramic machine (Planmeca PM 2002 CC Proline; Helsinki, Finland) by a radiology technician. One researcher evaluated each image according to patient positioning, head alignment and film density and contrast to avoid including radiographs with distortion.

\section{Radiographic measurements}

Images were digitized (300 dpi) with a flatbed scanner that had a transparency adapter (Epson Perfection V700 Photo/V750 Prol. Linear measurements were performed using specialized analytical software (Image J 1.42) at a correction for $30 \%$ magnification, relatively, to better simulate the clinical situation. Mandibular cortical width at the mental region (MCW), panoramic mandibular index (PMI), and morphologic classification of mandibular cortex (Mandibular Inferior Cortex grade) were assessed on the dental panoramic radiographs by an observer. Cortical width at the mental foremen region was assessed according to the technique described by Ledgerton et $\mathrm{al}^{21}$ in which the mental foremen is identified and a line traced perpendicular to the tangent to the lower border of the mandible and through the center of the mental foremen. The cortical width was measured bilaterally, and the mean cortical width was calculated. ${ }^{21}$

The mandibular cortical shape is classified into one of three groups according to the method of Klemetti et al:22 $\mathrm{C} 1$-the endosteal cortical margin is even and sharp on both sides, normal cortex 
(Figure 1); C2-the endosteal margin has semilunar defects (lacunar resorption) or endosteal cortical residues on one or both sides (Figure 2), mild to moderate cortex erosion; C3-the cortical layer forms heavy endosteal cortical residues and is clearly porous, severely eroded cortex (Figure 3). The thickness of the mandibular cortex was divided by the distance between the mental foremen and the inferior mandibular cortex to obtain the PMI. ${ }^{15}$

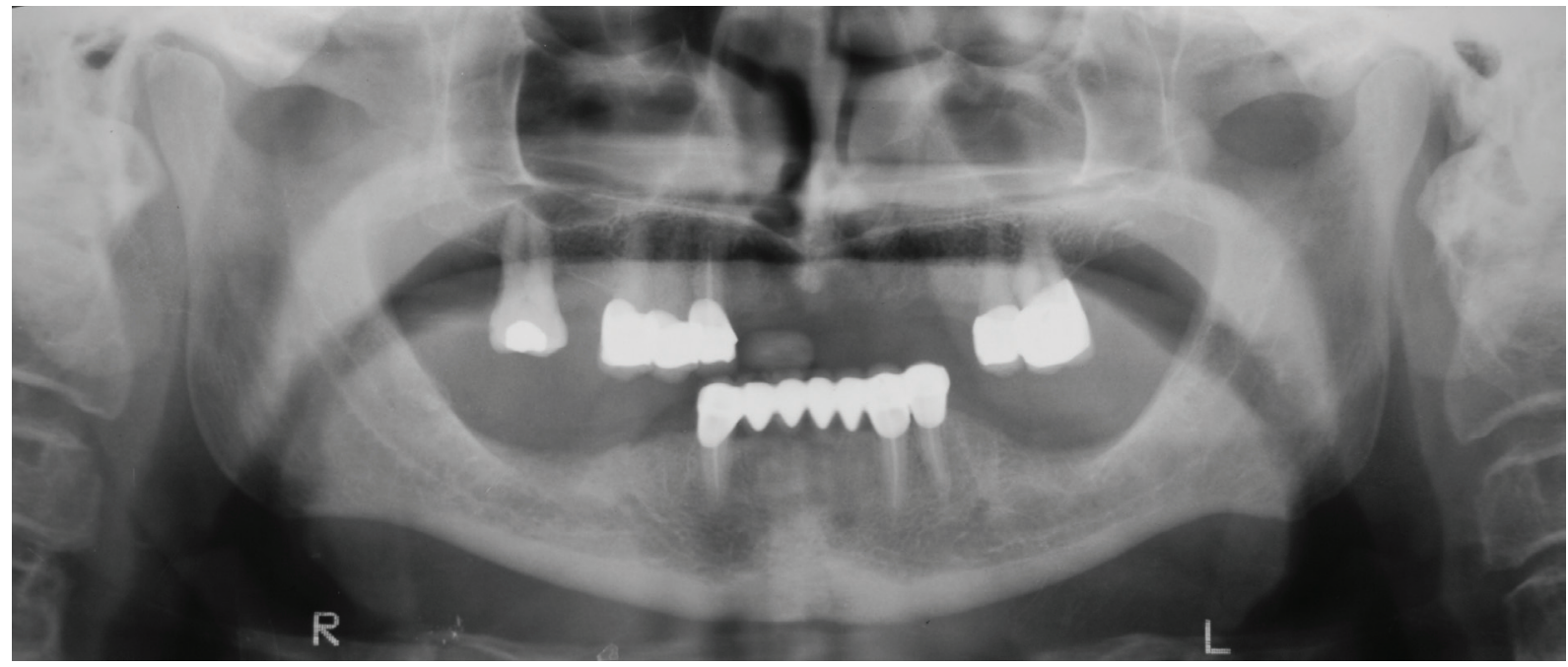

Figure 1. Example of category $\mathrm{C} 1$ of the mandibular cortex index.

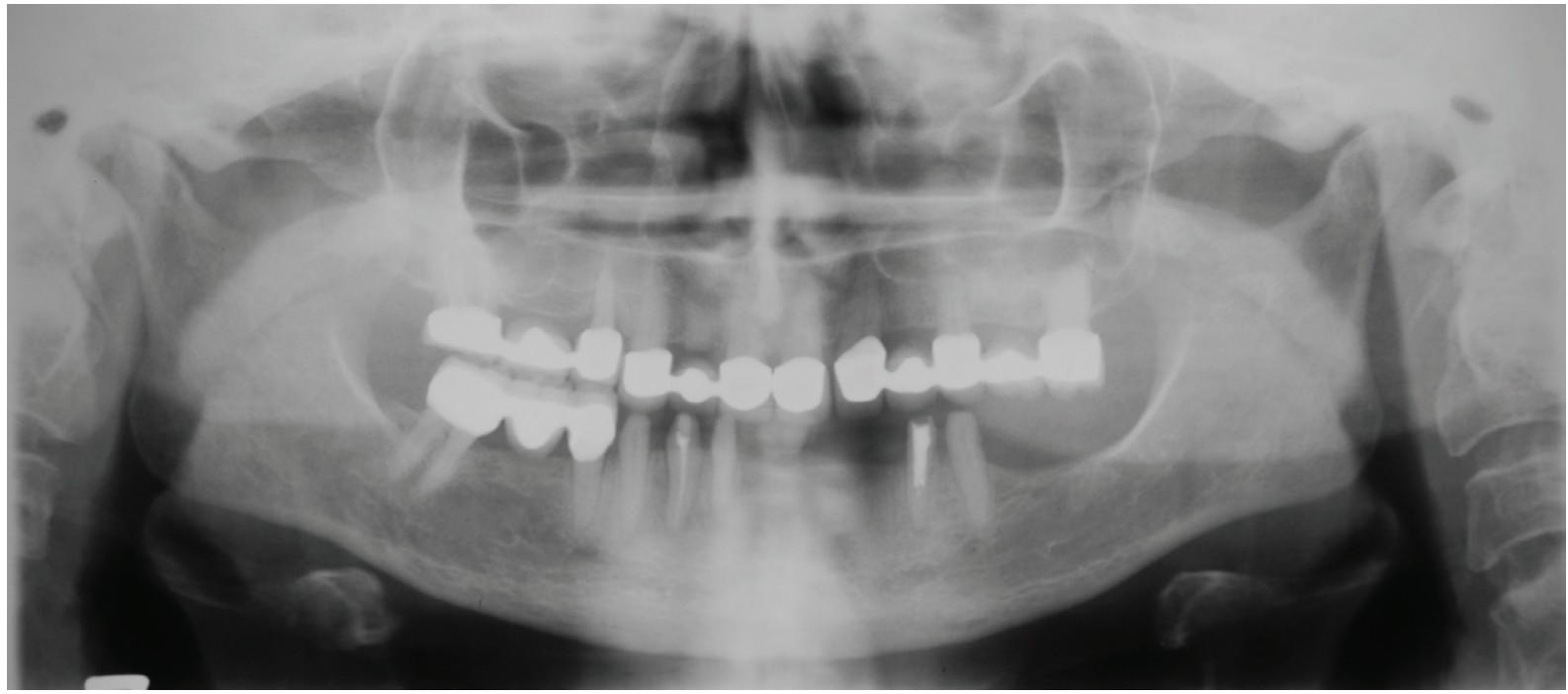

Figure 2. Example of category C2 of the mandibular cortex index.

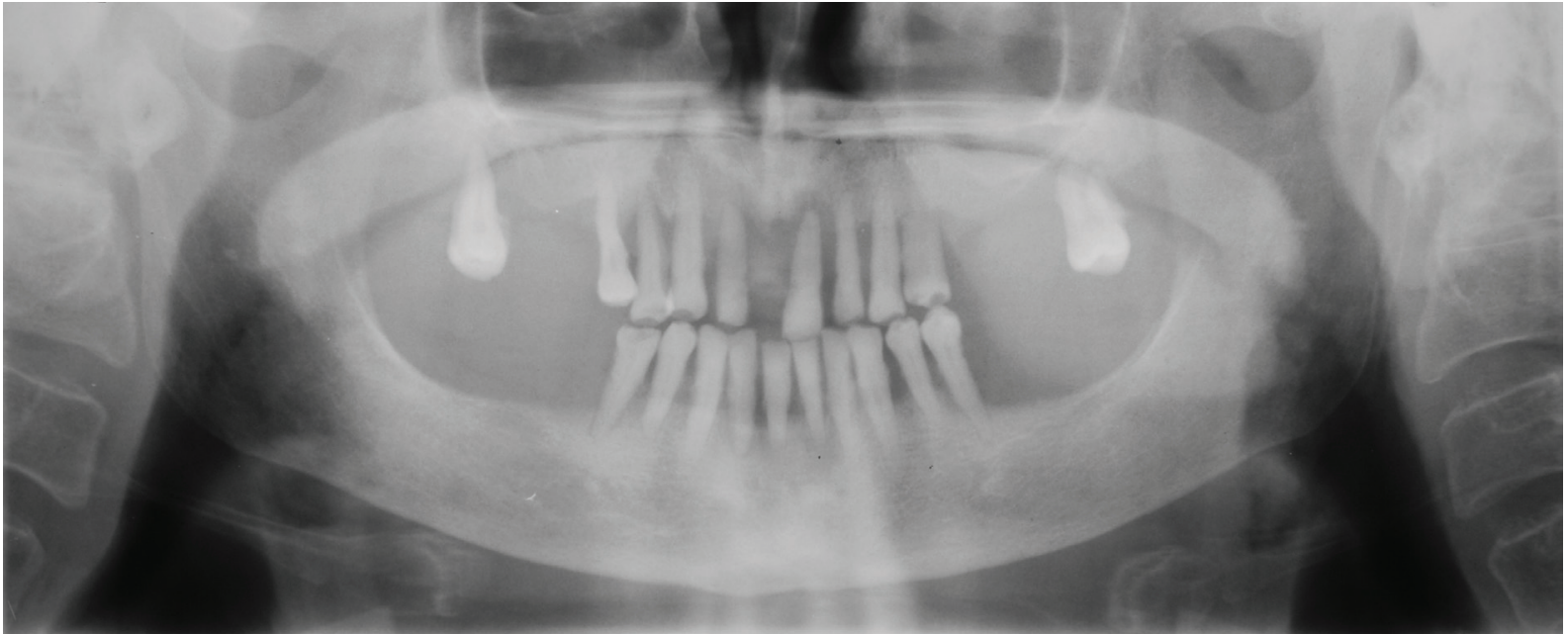

Figure 3. Example of category $\mathrm{C} 3$ of the mandibular cortex index.

European Journal of Dentistry 
The dental status was established and dentate individuals were classified according to the presence of mandibular molars. Those individuals having mandibular molars were classified as dentate, whereas those without mandibular molars, but with other teeth present, were categorized as partially dentate. Three groups were created: 1) dentate, 2) partially dentate (missing all mandibular molars), and 3) edentulous.

All data were analyzed using the Statistical Package for the Social Sciences (SPSS) V.17.0 (SPSS Inc. Chicago, Illinois, USA). Descriptive statistics, cross-tabulations, and Chi-square statistics were computed with the statistical significance set at $\mathrm{P}<.05$.

\section{RESULTS}

Of the 487 patients participating in the study, $239(49.1 \%)$ were men and 248 (50.9\%) were women. The mean age of the study population was $67.93 \pm 6.07$ years. Table 1 shows the gender and dental status characteristics of the study sample. Distribution according to gender and the number of subjects with osteoporosis and without osteoporosis was shown in Table 2.

There was a significant difference between females and males for MCW and PMI values. While mean mandibular cortical width values (normal value: $\geq 3 \mathrm{~mm}$ as suggested by Devlin and Horner ${ }^{9}$ ] and panoramic mandibular index values (normal value: $\geq 0.3$ as suggested by Benson et $\mathrm{al}^{15}$ ) were

Table 1. Characteristics of the sample.

\begin{tabular}{lcc}
\hline Characteristics & $\mathrm{n}$ & $\%$ \\
\hline Gender & 239 & \\
Male & 248 & 59.1 \\
Female & & 50.9 \\
\hline Dental status & 57 & \\
Dentate & 322 & 11.7 \\
Partial & 108 & 66.1 \\
Edentulous & 22.2 \\
\hline
\end{tabular}

Table 2. Distribution according to gender and the number of subjects with osteoporosis and without osteoporosis.

\begin{tabular}{lccc}
\hline & & With osteoporosis & Without osteoporosis \\
\hline & & $\mathrm{n}(\%)$ & $\mathrm{n}(\%)$ \\
\hline \multirow{2}{*}{ Gender } & Male & $8(6.3)$ & $231(64.0)$ \\
& Female & $118(93.7)$ & $130(36.0)$ \\
\multirow{2}{*}{ Total } & & $126(25.9)$ & $361(74.1)$ \\
\hline
\end{tabular}

normal in men over 60 years, the mean mandibular cortical width values and panoramic mandibular index values decreased significantly in women of the same age group. Dental status was statistically significantly associated with the mandibular cortical width and panoramic mandibular index. There was a significant difference for MCW and PMI values according to dental status (Table 3 ). MCW and PMI values of edentulous patients were significantly lower.

Categories of $\mathrm{MCl}$ (C1/53.0\%, $\mathrm{C} 2 / 45.6 \%$, C3/1.4\%) were detected. There was a significant difference in the categories of $\mathrm{MCl}$ between men and women. Category $\mathrm{C} 1$ was more frequently seen in men; Category C2 was more frequently seen in women; and category C3 was observed only in women. Dental status was significantly different according to the categories of $\mathrm{MCl}$ (Table 4).

Categories of $\mathrm{MCl}$ were determined according to osteoporotic status. While category $\mathrm{C} 1$ was more frequently seen on patients without osteoporosis, category C2 was more frequently seen on patients with osteoporosis (Table 5).

While the mean mandibular cortical width value was $2.88 \mathrm{~mm}$ on patients with osteoporosis, this value was $3.70 \mathrm{~mm}$ on patients without osteoporosis. The mean panoramic mandibular index value was 0.27 on patients with osteoporosis, and 0.32 on patients without osteoporosis.

The number of osteoporotic patients who had a normal mandibular cortical width value ( $\geq 3 \mathrm{~mm}$ ) was less than the number of non-osteoporotic patients with a normal mandibular cortical width value; but the number of non-osteoporotic patients with a subnormal mandibular cortical width value was higher than the number of osteoporotic

Table 3. Mean (SD) mandibular cortical width (MCW) (mm) and panoramic mandibular index (PMI) values according to gender and dental status.

\begin{tabular}{lcc}
\hline & MCW & PMI \\
\hline & Mean (SD) & Median (Min-Max) \\
\hline Gender & & \\
Male & $4.08(0.86)$ & $0.34(0.12-0.51)$ \\
Female & $2.92(0.97)$ & $0.27(0.07-0.52)$ \\
\hline Dental Status & & \\
Dentate & $3.82(0.98)$ & $0.32(0.12-0.52)$ \\
Partially Dentate & $3.63(1.06)$ & $0.31(0.07-0.51)$ \\
Edentulous & $2.90(1.02)$ & $0.27(0.07-0.51)$ \\
\hline
\end{tabular}


patients with a below normal mandibular cortical width value $(<3 \mathrm{~mm})$. The number of non-osteoporotic patients who had a subnormal panoramic mandibular index value $(<0.3)$ was higher than the number of osteoporotic patients with a subnormal panoramic mandibular index value. Thus, there were statistically differences between mandibular cortical width and panoramic mandibular index values in patients with osteoporosis and without osteoporosis $(\mathrm{P}<.05)$.

According to dental status, more edentulous patients had osteoporosis than did patients who were partially dentate and dentate. The number of dentate patients with osteoporosis was the lowest, compared with other dental statuses (Table 6). Osteoporotic status was statistically significantly associated with dental status $(\mathrm{P}<.05)$.

\section{DISCUSSION}

Cortical width and porosity on dental panoramic radiographs have been shown to be potentially useful assessment methods. ${ }^{10,23}$ Therefore, this study used the panoramic $\mathrm{MCl}, \mathrm{MI}$ and $\mathrm{PMI}$ radiomorphometric indices to evaluate individuals' risk of osteoporosis.

Measurement of the thickness of the mandibular cortical width in panoramic radiographs has

Table 4. Distribution according to gender and dental status of categories of $\mathrm{MCl}$.

\begin{tabular}{|c|c|c|c|c|}
\hline \multicolumn{5}{|c|}{$\mathrm{MCl}$ classification } \\
\hline & C1 & $\mathrm{C} 2$ & C3 & Total \\
\hline & $n(\%)$ & $n(\%)$ & $\mathrm{n}(\%)$ & $n(\%)$ \\
\hline \multicolumn{5}{|l|}{ Gender } \\
\hline Male & $187(78.2)$ & $52(21.8)$ & $0(.0)$ & 239 (49.1) \\
\hline Female & $71(28.6)$ & 170 (68.5) & $7(2.8)$ & 248 (50.9) \\
\hline Total & $258(53.0)$ & $222(45.6)$ & $7(1.4)$ & $487(100)$ \\
\hline \multicolumn{5}{|l|}{ Dental status } \\
\hline Dentate & $37(64.9)$ & $20(35.1)$ & $0(0)$ & 57 (11.7) \\
\hline Partially dentate & $179(55.6)$ & 139 (43.2) & $4(1.2)$ & $322(66.1)$ \\
\hline Edentulous & 42 (38.9) & 63 (58.3) & $3(2.8)$ & 108 (22.2) \\
\hline
\end{tabular}

Table 5. Categories of $\mathrm{MCl}$ according to osteoporosis circumstance.

\begin{tabular}{|c|c|c|c|}
\hline & \multicolumn{3}{|c|}{$\mathrm{MCl}$ classification } \\
\hline & C1 & C2 & C3 \\
\hline & n (\%) & n (\%) & $\mathrm{n}(\%)$ \\
\hline With osteoporosis & $32(25.4)$ & 90 (71.4) & $4(3.2)$ \\
\hline Without osteoporosis & $226(62.6)$ & $132(36.6)$ & $3(0.8)$ \\
\hline
\end{tabular}

been suggested as a way to predict patients with low bone mineral density. ${ }^{4}$ Previous studies have shown significant relationships between the MCW and bone mineral density. ${ }^{9-11,16,24-27}$ In the current study, the cortical bone in the mental region was significantly thinner in individuals with osteoporosis. This result was expected as it concurs with previous studies. ${ }^{10,25,28-32}$ The present study revealed that the mean MCW value on patients with osteoporosis was smaller than on patients without osteoporosis. A few studies ${ }^{4,8,19,33,34}$ have evaluated the changes in mandibular cortical thickness for males. Dutra et $\mathrm{al}^{4}$ observed higher values for MCW in men. The results of a study by KnezovicZlataric et $a^{34}$ suggest that the values begin to decrease sharply for women as compared to men. Devlin and Horner ${ }^{9}$ reported that a cortical width of $3 \mathrm{~mm}$ is the most appropriate threshold for referral for bone densitometry. White et $\mathrm{al}^{14}$ believe that it is more appropriate to post the threshold in the mid $4 \mathrm{~mm}$ range. Klemetti et al ${ }^{12}$ reported that a threshold of $4 \mathrm{~mm}$ is optimal, but not sufficient the present study, a cortical width of $3 \mathrm{~mm}$ was used as a threshold. Though mean mandibular cortical width values (normal value: $\geq 3 \mathrm{~mm}$ ) are normal in men over 60 years, mean mandibular by itself for excellent classification of subjects. In 
cortical width values are decreased significantly in women of the same age group.

Horner and Devlin ${ }^{25}$ have shown that the panoramic mandibular index can be used for evaluation of osteoporosis status. According to Benson et $\mathrm{al}^{15}$ mean panoramic mandibular index values increase in the elderly. Recent studies about PMI values that have been performed primarily on women have found PMI values between 0.31$0.38,15,25,35$ which are higher than the mean value of 0.27 found in our study. Horner and Devlin ${ }^{25}$ suggested that the PMI has no significant advantage over the MCW, whereas Drozdzowska et al ${ }^{29}$ concluded that the PMI might be used as an indicator of bone mineral changes when PMI values deviate markedly from the mean PMI of the population. However, as panoramic indices were usually evaluated on women, ${ }^{4,25,32,35}$ data related to differences between genders were limited. In the present study, the cut-off value for the PMI was 0.30, and while the mean PMI value was 0.34 on men, it was 0.27 on women. It may be supposed that the reason for the differences between genders is that women more often have osteoporosis. There was a significant difference between females and males for PMI values. However, while the mean panoramic mandibular index value was 0.27 on patients with osteoporosis, this value was 0.32 on patients without osteoporosis.

Knezovic -Zlataric et $\mathrm{al}^{34}$ found no difference in the distribution of women and men between $\mathrm{MCl}$ categories C2 and C3. Knezovic -Zlataric et $\mathrm{al}^{34}$ also reported that the age-related distribution of $\mathrm{MCl}$ showed an age-related increase in the numbers of individuals with C3 cortex appearance, and a significantly higher incidence of women who had C3 cortexes in an older age group. In the present study, $\mathrm{MCl}$ values were significantly affected by gender, as $68.5 \%$ and $2.8 \%$ of women had eroded mandibular cortex (C2 and C3), respectively, whereas only $21.8 \%$ and $0 \%$ of men had eroded mandibular cortex (C2 and $\mathrm{C} 3$ ), respectively, and

Table 6. Dental status on patients with and without osteoporosis.

\begin{tabular}{lcc}
\hline & With osteoporosis & Without osteoporosis \\
\hline Dentate & $\mathrm{n}(\%)$ & $\mathrm{n}(\%)$ \\
\hline Partially dentate & $12(9.5)$ & $45(12.5)$ \\
Edentulous & $70(55.6)$ & $252(69.8)$ \\
\hline
\end{tabular}

only women were in category C3. In the study by Yüzügüllü et al, ${ }^{8} 25 \%$ and $75 \%$ of women over 60 years had eroded mandibular cortex according to categories C2 and C3, respectively. The difference between the two studies is attributed to different sample sizes.

Some studies have found that low bone mineral density is related with high $\mathrm{MCl}$ values (C3), which can be extrapolated to clinical practice. ${ }^{11,12,22,29,34-36}$ In the present study, $3.2 \%$ of patients with osteoporosis had category $\mathrm{C} 3$, and $71.4 \%$ of patients with osteoporosis had Category C2. No males were in category $\mathrm{C} 3$, but $93.7 \%$ of the patients with osteoporosis were women, which may be the reason why C3 consisted of only women.

Some studies have evaluated the interactions of radiomorphometric indices with dental status. ${ }^{4,19,35}$ A study by Ledgerton et $\mathrm{al}^{35}$ showed a significant relationship between dental status and the $\mathrm{MCW}, \mathrm{PMI}$, and $\mathrm{MCl}$ indices. In another study by Uysal et $\mathrm{al}^{37} \mathrm{MCl}$ was found to be significantly affected by the status of dentition. Gulsahi et al $^{19}$ found that one of the most important parameters affecting $\mathrm{MCl}$ was dental status. Contrary to the foregoing studies, a study by Dutra et $\mathrm{al}^{4}$ found no significant association between dental status and MCW. The study by Gulsahi et al ${ }^{19}$ demonstrated that edentulous patients with osteoporosis may be identified with sufficient diagnostic efficacy by use of the $\mathrm{MCl}$ and $\mathrm{MCW}$, but not by use of the PMI. In addition, Drozdzowska et al ${ }^{29}$ studied 30 healthy, postmenopausal, edentulous women divided into normal, osteopenic, and osteoporotic groups and found no significant difference in the mean PMI. In our study, there was a significant difference for MCW and PMI values according to dental status, as the MCW and PMI values of edentulous patients were significantly lower. Dental status was also significantly different for categories of $\mathrm{MCl}$. Most of the patients who were in categories $\mathrm{C} 1, \mathrm{C} 2$, and C3 $(55.6 \%, 43.2 \%$, and $1.2 \%$, respectively) were partially dentate. Edentulous patients appeared to have higher values for categories of $\mathrm{MCl}$. Most patients who were in Category C3 were partially dentate. These results supported the hypothesis that the lack of full occlusion causes insufficient occlusal forces to be projected to the mandible, which may affect the mandibular cortex, resulting in higher $\mathrm{MCl}$ values. ${ }^{37}$ However, because the mean age of the study population was 67.93 years 
and because reduction of bone mass density is associated with age (especially in women), as well as decreased mean mandibular cortical width values, the higher $\mathrm{MCl}$ values in women were the expected result.

\section{CONCLUSIONS}

We have described a statistical relationship between osteoporotic status and radiomorphometric indices (MCW, MCl, PMI), as linked to dental status and gender. In conclusion, our study showed that there were statistically significant differences according to gender and dental status in the MCW, $\mathrm{MCl}$, and $\mathrm{PMI}$ values between patients with and without osteoporosis.

\section{REFERENCES}

1. Rizzoli R, Bruyere O, Cannata-Andia JB, Devogelaer JP, Lyritis G, Ringe JD, Vellas B, Reginster JY. Management of osteoporosis in the elderly. Curr Med Res Opin 2009;25:23732387.

2. Karasik D. Osteoporosis: an evolutionary perspective. Hum Genet 2008;124:349-356.

3. Karayianni K, Horner K, Mitsea A, Berkas L, Mastoris M, Jacobs R, Lindh C, van der Stelt PF, Harrison E, Adams JE, Pavitt S, Devlin H. Accuracy in osteoporosis diagnosis of a combination of mandibular cortical width measurement on dental panoramic radiographs and a clinical risk index (OSIRIS): the OSTEODENT project. Bone 2007;40:223-229.

4. Dutra V, Yang J, Devlin H, Susin C. Radiomorphometric indices and their relation to gender, age, and dental status. Oral Surg Oral Med Oral Pathol Oral Radiol Endod 2005;99:479-484.

5. Bollen AM, Taguchi A, Hujoel PP, Hollender LG. Casecontrol study on self-reported osteoporotic fractures and mandibular cortical bone. Oral Surg Oral Med Oral Pathol Oral Radiol Endod 2000;90:518-524

6. Horner K, Devlin H. Clinical bone densitometric study of mandibular atrophy using dental panoramic tomography. J Dent 1992;20:33-37.

7. Law AN, Bollen AM, Chen SK. Detecting osteoporosis using dental radiographs: a comparison of four methods. J Am Dent Assoc 1996;127:1734-1742.

8. Yüzügüllü B, Gulsahi $A$, Imirzalioglu P. Radiomorphometric indices and their relation to alveolar bone loss in completely edentulous Turkish patients: a retrospective study. J Prosthet Dent 2009;101:160-165.

9. Devlin H, Horner K. Mandibular radiomorphometric indices in the diagnosis of reduced skeletal bone mineral density. Osteoporos Int 2002;13:373-378.
10. Devlin H, Karayianni K, Mitsea A, Jacobs R, Lindh C, van der Stelt P, Marjanovic E, Adams J, Pavitt S, Horner K. Diagnosing osteoporosis by using dental panoramic radiographs: the OSTEODENT project. Oral Surg Oral Med Oral Pathol Oral Radiol Endod 2007;104:821-828.

11. Taguchi A, Suei Y, Ohtsuka M, Otani K, Tanimoto K, Ohtaki $M$. Usefulness of panoramic radiography in the diagnosis of postmenopausal osteoporosis in women. Width and morphology of inferior cortex of the mandible. Dentomaxillofac Radiol 1996;25:263-267.

12. Klemetti E, Kolmakow S. Morphology of the mandibular cortex on panoramic radiographs as an indicator of bone quality. Dentomaxillofac Radiol 1997;26:22-25.

13. Nakamoto T, Taguchi A, Ohtsuka M, Suei Y, Fujita M, Tanimoto K, Tsuda M, Sanada M, Ohama K, Takahashi J, Rohlin $M$. Dental panoramic radiograph as a tool to detect postmenopausal women with low bone mineral density: untrained general dental practitioners' diagnostic performance. Osteoporos Int 2003;14:659-664.

14. White SC, Taguchi A, Kao D, Wu S, Service SK, Yoon D, Suei Y, Nakamoto T, Tanimoto K. Clinical and panoramic predictors of femur bone mineral density. Osteoporos Int 2005; 16:339-346.

15. Benson BW, Prihoda TJ, Glass BJ. Variations in adult cortical bone mass as measured by a panoramic mandibular index. Oral Surg Oral Med Oral Pathol 1991;71:349-356.

16. Vlasiadis KZ, Skouteris CA, Velegrakis GA, Fragouli I, Neratzoulakis JM, Damilakis J, Koumantakis EE. Mandibular radiomorphometric measurements as indicators of possible osteoporosis in postmenopausal women. Maturitas 2007;58:226-235.

17. Cakur B, Sahin A, Dagistan S, Altun O, Caglayan F, Miloglu 0 , Harorli A. Dental panoramic radiography in the diagnosis of osteoporosis. J Int Med Res 2008;36:792-799.

18. Taguchi A, Suei $Y$, Sanada M, Ohtsuka M, Nakamoto $T$, Sumida H, Ohama K, Tanimoto K. Validation of dental panoramic radiography measures for identifying postmenopausal women with spinal osteoporosis. Am J Roentgenol 2004;183:1755-1760.

19. Gulsahi A, Yüzügüllü B, Imirzalioglu P, Genç Y. Assessment of panoramic radiomorphometric indices in Turkish patients of different age groups, gender and dental status. Dentomaxillofac Radiol 2008;37:288-292.

20. Gulsahi A, Ozden S, Cebeci Al. The relationship between panoramic radiomorphometric indices and the femoral bone mineral density of edentulous patients. Oral Radiol 2009;25:47-52. 
21. Ledgerton D, Horner K, Devlin H, Worthington H. Panoramic mandibular index as a radiomorphometric tool: an assessment of precision. Dentomaxillofac Radiol 1997;26:95100.

22. Klemetti E, Kolmakov S, Kröger H. Pantomography in assessment of the osteoporosis risk group. Scand J Dent Res 1994;102:68-72.

23. Halling A, Persson GR, Berglund J, Johansson O, Renvert S. Comparison between the Klemetti index and heel DXA BMD measurements in the diagnosis of reduced skeletal bone mineral density in the elderly. Osteoporos Int 2005; 16:999-1003.

24. Klemetti E, Kolmakov S, Heiskanen P, Vainio P, Lassila V. Panoramic mandibular index and bone mineral densities in postmenopausal women. Oral Surg Oral Med Oral Pathol 1993;75:774-779.

25. Horner K, Devlin H. The relationship between mandibular bone mineral density and panoramic radiographic measurements. J Dent 1998;26:337-343

26. Taguchi A, Ohtsuka M, Tsuda M, Nakamoto T, Kodama I, Inagaki K, Noguchi T, Kudo Y, Suei Y, Tanimoto K. Risk of vertebral osteoporosis in post-menopausal women with alterations of the mandible. Dentomaxillofac Radiol 2007;36:143-148.

27. Okabe S, Morimoto Y, Ansai T, Yoshioka I, Tanaka T, Taguchi A, Kito S, Wakasugi-Sato N, Oda M, Kuroiwa H, Ohba T, Awano S, Takata Y, Takehara T. Assessment of the relationship between the mandibular cortex on panoramic radiographs and the risk of bone fracture and vascular disease in 80-year-olds. Oral Surg Oral Med Oral Pathol Oral Radiol Endod 2008;106:433-442.

28. Dutra V, Devlin H, Susin C, Yang J, Horner K, Fernandes AR. Mandibular morphological changes in low bone mass edentulous females: evaluation of panoramic radiographs. Oral Surg Oral Med Oral Pathol Oral Radiol Endod 2006;102:663-668.

29. Drozdzowska B, Pluskiewicz W, Tarnawska B. Panoramicbased mandibular indices in relation to mandibular bone mineral density and skeletal status assessed by dual energy X-ray absorptiometry and quantitative ultrasound. Dentomaxillofac Radiol 2002;31:361-367.

30. Ishii K, Taguchi A, Nakamoto T, Ohtsuka M, Sutthiprapaporn P, Tsuda M, Kodama I, Kudo Y, Sumida H, Suei Y, Tanimoto K. Diagnostic efficacy of alveolar bone loss of the mandible for identifying postmenopausal women with femoral osteoporosis. Dentomaxillofac Radiol 2007;36:28-33.

31. Horner K, Devlin H, Harvey L. Detecting patients with low skeletal bone mass. J Dent 2002;30:171-175.
32. Taguchi A, Tsuda M, Ohtsuka M, Kodama I, Sanada M, Nakamoto T, Inagaki K, Noguchi T, Kudo Y, Suei Y, Tanimoto K, Bollen AM. Use of dental panoramic radiographs in identifying younger postmenopausal women with osteoporosis. Osteoporos Int 2006;17:387-394.

33. Bras J, van Ooij CP, Abraham-Inpijn L, Kusen GJ, Wilmink JM. Radiographic interpretation of the mandibular angular cortex: A diagnostic tool in metabolic bone loss. Part I. Normal state. Oral Surg Oral Med Oral Pathol 1982;53:541545.

34. Knezović Zlatarić D, Celebić A, Lazić B, Baucić I, Komar D, Stipetić-Ovcaricek J, Ibrahimagić L. Influence of age and gender on radiomorphometric indices of the mandible in removable denture wearers. Coll Antropol 2002;26:259266.

35. Ledgerton D, Horner K, Devlin H, Worthington H. Radiomorphometric indices of the mandible in a British female population. Dentomaxillofac Radiol 1999;28:173-181.

36. Tözüm TF, Taguchi A. Role of dental panoramic radiographs in assessment of future dental conditions in patients with osteoporosis and periodontitis. N Y State Dent $J$ 2004;70:32-35.

37. Uysal S, Caḡirankaya BL, Hatipoḡlu MG. Do gender and torus mandibularis affect mandibular cortical index? A cross-sectional study. Head Face Med 2007;3:37. 